Article

\title{
Performance of 1-(3-Sulfopropyl)-3- Methylimidazolium Hydrogen Sulfate as a Catalyst for Hardwood Upgrading into Bio-Based Platform Chemicals
}

\author{
Mar López®, Sandra Rivas ${ }^{\circledR}$, Carlos Vila $₫$, Valentín Santos $₫$ and Juan Carlos Parajó * \\ Chemical Engineering Department, University of Vigo (Campus Ourense), Polytechnical Building, As Lagoas, \\ 32004 Ourense, Spain; marlopezr@uvigo.es (M.L.); sandrarivas@uvigo.es (S.R.); cvila@uvigo.es (C.V.); \\ vsantos@uvigo.es (V.S.) \\ * Correspondence: jcparajo@uvigo.es; Tel.: +34-988-387-033
}

Received: 25 July 2020; Accepted: 12 August 2020; Published: 15 August 2020

\begin{abstract}
The acidic ionic liquid 1-(3-sulfopropyl)-3-methylimidazolium hydrogen sulfate $\left(\left[\mathrm{C}_{3} \mathrm{SO}_{3} \mathrm{Hmim}\right] \mathrm{HSO}_{4}\right)$ was employed as a catalyst for manufacturing polysaccharide-derived products (soluble hemicellulose-derived saccharides, furans, and/or organic acids) from Eucalyptus globulus wood. Operation was performed in aqueous media supplemented with $\left[\mathrm{C}_{3} \mathrm{SO}_{3} \mathrm{Hmim}\right] \mathrm{HSO}_{4}$ and methyl isobutyl ketone, following two different processing schemes: one-pot reaction or the solubilization of hemicelluloses by hydrothermal processing followed by the separate manufacture of the target compounds from both hemicellulose-derived saccharides and cellulose. Depending on the operational conditions, the one-pot reaction could be directed to the formation of furfural (at molar conversions up to $92.6 \%$ ), levulinic acid (at molar conversions up to $45.8 \%$ ), or mixtures of furfural and levulinic acid (at molar conversions up to $81.3 \%$ and $44.8 \%$, respectively). In comparison, after hydrothermal processing, the liquid phase (containing hemicellulose-derived saccharides) yielded furfural at molar conversions near $78 \%$, whereas levulinic acid was produced from the cellulose-enriched, solid phase at molar conversions up to $49.5 \%$.
\end{abstract}

Keywords: acidic ionic liquid; Eucalyptus wood; furfural; levulinic acid

\section{Introduction}

Mankind is facing key challenges related to environmental issues and sustainability, caused by the massive utilization of fossil resources, which currently provide more than $90 \%$ of our energy needs and feedstocks of the chemical industry [1]. The development of new processes based on renewable vegetal biomass (the most important source of organic carbon on earth) as a feedstock is one of the strategic ways pointed out to deal with these problems. In this field, the "lignocellulose biorefinery" concept, based on the selective separation of the major components making part of lignocellulosic biomass (LB), allows the manufacture of diverse bio-based platform chemicals, including furans and levulinic acid.

The term LB is used to name the numerous types of vegetal biomass mainly made up of polysaccharides (hemicelluloses and cellulose) and an aromatic fraction (lignin). These polymeric components are known as "structural components" of LB, and they appear together with non-structural components (extractives, ash, etc.), which are not important for the objectives of this study. Hardwoods possess a high content of structural components (typically, about $90 \mathrm{wt} \%$ ), with a hemicellulose fraction mainly made up of heteroxylan.

Eucalyptus spp. is the world's most widely planted hardwood species. Its fast, uniform growth, self-pruning, and ability to coppice make it favorable for applications as timber, pulpwood, or bioenergy 
feedstocks; as a result, it is one of the most productive and economically viable biomass crops in the world, with expansive commercialization on all populated continents [2].

Additionally, Eucalyptus woods show a number of favorable features to be used as industrial feedstocks, including compositional factors (comparative high cellulose content, hemicelluloses mainly made up by acetylated glucuronoxylan), as well as high density and growth rate [3,4]. Eucalyptus globulus wood is one of the most important commercial Eucalyptus species, and it represents a basic forest resource in the Atlantic regions of the Iberian Peninsula $[5,6]$.

The industrial utilization of LB can be achieved on the basis of the biorefinery concept, which proposes the sustainable processing of biomass into a spectrum of marketable products and energy, including biodegradable plastics, platform chemicals and other bio-based compounds, and advanced biofuels [4,7]. In this field, furfural and levulinic acid have been included among the top platform chemicals that can be manufactured based on green chemistry [7].

Most studies dealing with lignocellulose biorefineries employ the biochemical route, based on pretreatment and further hydrolysis fermentation of cellulose and/or hemicelluloses. Alternatively, processing schemes based on the acidic processing of wood to cause the hydrolysis-dehydration or hydrolysis-dehydration-rehydration of polysaccharides, provide a suitable framework for a fully chemical lignocellulose biorefinery having furfural (FF), hydroxymethylfurfural (HMF), and/or organic acids (levulinic acid, denoted LevA; and formic acid, denoted FA) as target products. For the purposes of this study, FF, LevA, and FA are of special importance, since:

- FF is one of the most important bio-based products derived from biomass [8], with important industrial applications and huge potential as an intermediate for producing a scope of chemicals and biofuels [9-11]

- LevA is a platform chemical with a rich chemistry, which can be used for manufacturing polymers or biofuels [12-14]

- FA is a commodity chemical employed in many industries, and it may also play a role in the development of fuel cells [15].

Eucalyptus globulus can be employed as a raw material for biorefineries following diverse processing schemes, including the ones shown in Figure 1a,b.

(a) One-pot processing of wood in aqueous media containing an acidic catalyst, in order to obtain FF from hemicelluloses, and HMF or organic acids (LevA, FA) from cellulose. Ionic liquids (IL) with acidic characteristics (acidic ionic liquids, AIL) can be used as the acidic catalyst.

(b) Solubilization of hemicelluloses by hydrothermal processing with hot, compressed water (leading to the breakdown of xylan chains into soluble saccharides), with further acid-catalyzed conversion of the reaction products into FF, and the acid-catalyzed manufacture of HMF and/or organic acids from the cellulose-rich, solid phase. As before, AIL can be employed as catalysts. 
a) One-pot conversion of wood

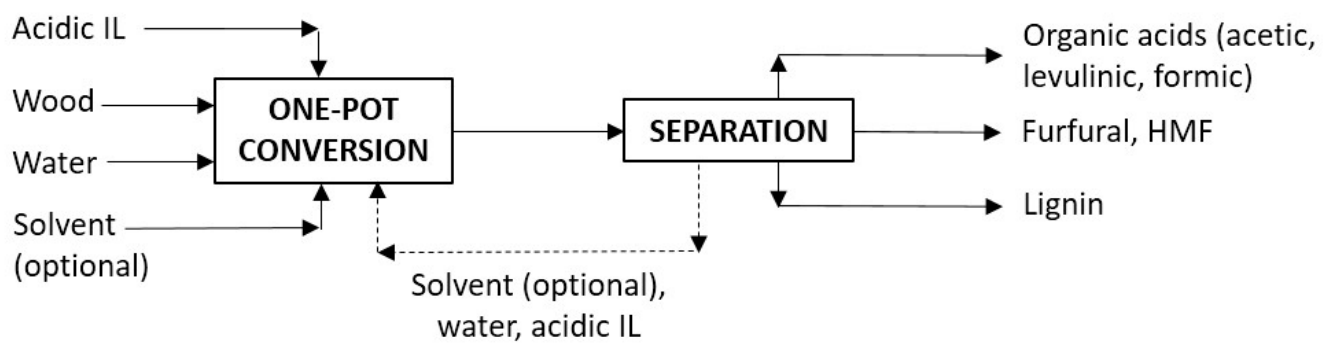

b) Wood conversion based on hemicellulose separation

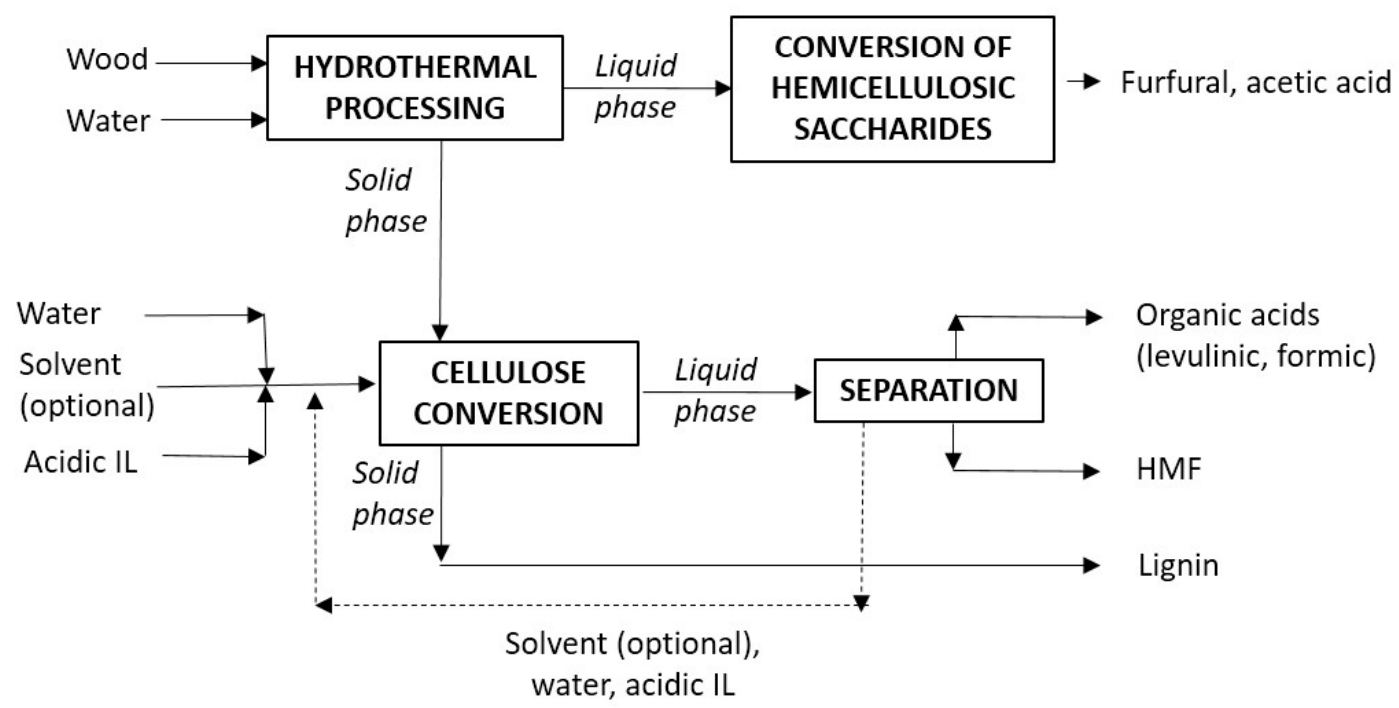

Figure 1. Processing schemes leading to the acid-catalyzed manufacture of furans and organic acids from wood. (a) One-pot approach. (b) Approach based on hemicellulose separation before furfural manufacture and cellulose conversion.

Each of these processing alternatives shows advantages and disadvantages with respect to each other: one-pot methods are easy to carry out and present a simple structure, requiring little equipment for reaction, and limited manpower [16]. However, the faster kinetics of FF generation/consumption with respect to the reactions leading to the formation/consumption of HMF and/or organic acids [17] means that some FF loss (or an incomplete formation of HMF/organic acids) has to be assumed. Alternatively, processes based on hemicellulose removal and the separate conversion of hemicellulose-derived saccharides and cellulose may increase selectivity and yields, but entail more reaction and downstream stages.

The kinetics of FF and HMF/LevA/FA formation from polysaccharides in aqueous, acidic media show complex mechanisms, which include the generation of reactive intermediates and the participation of these latter (together with the target products) into a number of series and parallel reactions, leading to the formation of humin-type products, which limit the yields of the target products [18-24].

A number of approaches have been proposed to improve the production of target products, including:

- Utilization of reaction media containing an immiscible solvent able to extract the target products, avoiding the unwanted reactions taking place in aqueous media [25-27]. This approach has been followed in this study, in which methyl isobutyl ketone (MIBK), a green solvent recommended by the CHEM21 guide [28], has been employed. 
- Utilization of microwave (MW)-heated reactors enabling fast heating profiles, which are considered favorable to improve the experimental results [29], and to allow energy savings [30]. Following this idea, a stirred, MW-heated reactor has been employed in this work in experiments aiming at the manufacture of furans and/or organic acids.

- Utilization of efficient and selective catalysts. Mineral acids such as sulfuric acid have been widely used for biomass processing. Alternatively, acidic ionic liquids have been reported to have potential as catalysts with improved activity, selectivity, and stability, and to allow an easier separation and reutilization [31]. Specifically, AILs have been used as catalysts for processing LB (or fractions derived from it) in aqueous or biphasic media [9,32]. In this work, a Brønsted acidic, imidazolium-type IL has been used for manufacturing FF, LevA, and FA from Eucalyptus wood (or from fractions derived from it), following the general ideas shown in Figure 1. Additional literature information of the utilization of ILs in the framework of biorefineries is provided in the next paragraphs.

Owing to their "green" character and special physicochemical properties (particularly, low volatility and stability), ILs can play a number of roles in biorefineries, including physical separation, the formulation of reaction media, and utilization as catalysts [33]. In this context, the conversion of wood polysaccharides (or low molecular weight saccharides derived from hemicelluloses) in aqueous media catalyzed by Brønsted acidic ILs, eventually in the presence of an organic solvent, has been considered in the literature. $\mathrm{SO}_{3} \mathrm{H}$-functionalized ILs have been employed to achieve the dehydration of xylose into FF [34], whereas 1-butyl 3-methylimidazolium hydrogen sulfate ([bmim] $\mathrm{HSO}_{4}$ ) has been employed to convert the hemicellulose fraction of lignocellulosic biomass into hemicellulosic sugars and FF [35], and to produce FF from xylose or soluble hemicellulose-derived saccharides obtained by the hydrothermal processing of Eucalyptus wood [32], eventually in the presence of a cosolvent [36]. Dealing with the conversion of cellulose, 1-(3-sulfopropyl)-3-methylimidazolium hydrogen sulfate $\left(\left[\mathrm{C}_{3} \mathrm{SO}_{3} \mathrm{Hmim}\right] \mathrm{HSO}_{4}\right)$, alone or in combination with metal chlorides, has been employed for LevA production from pure cellulose [37]; whereas $\left[\mathrm{C}_{3} \mathrm{SO}_{3} \mathrm{Hmim}\right] \mathrm{HSO}_{4}$ and 1-(3-sulfobutyl)-3-methylimidazolium hydrogen sulfate $\left(\left[\mathrm{C}^{2} \mathrm{SO}_{3} \mathrm{Hmim}\right] \mathrm{HSO}_{4}\right)$ provided good results as catalysts for the conversion of Pinus pinaster wood polysaccharides [38]. Sulfonated ILs were successfully employed as catalysts to achieve the conversion of pure cellulose into LevA [26].

This work provides a quantitative assessment of the performance of $\left[\mathrm{C}_{3} \mathrm{SO}_{3} \mathrm{Hmim}\right] \mathrm{HSO}_{4}$ as a catalyst for Eucalyptus globulus wood processing in biphasic media, following both the one-pot approach (Figure 1a) and a method based on hemicellulose solubilization and the further conversion of hemicellulose-derived products and cellulose into the target products (Figure 1b). Hydrolysis-dehydration or hydrolysis-dehydration-rehydration reactions were performed in a stirred, MW-heated reactor. The experimental results obtained under diverse operational conditions are discussed in terms of the volumetric concentrations and molar conversions of the target products (FF, LevA, FA, and acetic acid) and intermediates (HMF) derived from polysaccharides.

\section{Results}

\subsection{Composition of Eucalyptus Globulus Wood}

For the purposes of this work, the relevant data concerning E. globulus wood are the contents of the structural components (cellulose, hemicelluloses, and lignin), and the relative amounts of the diverse hemicellulose components. The wood lot employed in this study contained, in oven-dry mass basis, $22.1 \% \pm 0.2 \%$ Klason lignin, $1.38 \pm 0.07$ acid soluble lignin, $44.4 \% \pm 0.2 \%$ cellulose, $15.6 \% \pm 0.2 \%$ xylan, $0.43 \% \pm 0.06 \%$ arabinosyl units, $0.90 \% \pm 0.06 \%$ mannosyl units, $1.02 \% \pm 0.03 \%$ galactosyl units, and $2.95 \% \pm 0.09 \%$ acetyl groups. This composition is typical for Eucalyptus globulus, as it can be seen in a recent review [4]. Among the above fractions, cellulose, galactosyl units, and mannosyl units are potential substrates for manufacturing HMF and/or LevA/FA; xylan and arabinosyl groups are potential substrates for FF manufacture; and acetyl groups yield acetic acid (AcH) upon hydrolysis. 


\subsection{One-Pot Conversion of Eucalyptus Globulus Wood}

In order to assess the ability of $\left[\mathrm{C}_{3} \mathrm{SO}_{3} \mathrm{Hmim}\right] \mathrm{HSO}_{4}$ as a catalyst for obtaining bio-based chemicals from Eucalyptus globulus wood polysaccharides, the set of experiments listed in Table 1 was performed using the MW-heated reactor. Operating at moderate catalyst loadings ( $0.10-0.15 \mathrm{~g} / \mathrm{g}$ oven-dry wood), operation was carried out at high water-to-solid ratios (6 or $10 \mathrm{~g} / \mathrm{g}$ oven-dry wood, which are markedly higher than the ones typically employed in MW reactors), keeping the relative amount of MIBK at 2 $\mathrm{g} / \mathrm{g}$ aqueous phase.

The first assay (experiment 1 in Table 1) was performed under mild conditions: the reaction media, made with the highest charges of solid and catalyst considered, was heated up to $170{ }^{\circ} \mathrm{C}$ and then cooled immediately (isothermal reaction time, $0 \mathrm{~min}$ ). The high solid yield ( $53.7 \mathrm{~g} / 100 \mathrm{~g}$ wood) indicated that the conversion of polysaccharides into the target products was incomplete, which was a fact confirmed by the concentrations of reaction intermediates in aqueous phase $(12.4 \mathrm{~g}$ glucose $/ \mathrm{L}$ and 18.6 and $g$ xylose/L). Interestingly, the conversion of xylan into xylose proceeded at $62.8 \%$ molar conversion, and the acetyl groups were almost quantitatively hydrolyzed into $\mathrm{AcH}$, which appears distributed in both aqueous and organic phases), confirming that $\left[\mathrm{C}_{3} \mathrm{SO}_{3} \mathrm{Hmim}\right] \mathrm{HSO}_{4}$ could be used for manufacturing hemicellulosic sugars. However, the concentrations of FF, HMF, FA, and LevA were low.

Based on these findings, the severity of the operational conditions was increased by raising the temperature to $180^{\circ} \mathrm{C}$ and keeping the rest of experimental variables unchanged. As expected, the solid yield decreased (to $38.5 \%$ ), the glucose concentration increased $(28.0 \mathrm{~g} / \mathrm{L}$ ) owing to the higher cellulose conversion, and the xylose concentration dropped to $8.18 \mathrm{~g} / \mathrm{L}$ owing to the increased generation of FF (which appeared concentrated in the organic phase, accounting for an overall molar conversion of $49 \%$, including the contributions of the aqueous and organic phases). Although the LevA concentrations increased up to 0.98 and $0.34 \mathrm{~g} / \mathrm{L}$ in the aqueous and organic phases, respectively, its overall molar conversion was still very poor $(3.40 \%)$. When the reaction conditions were modified by performing an isothermal reaction stage of $16 \mathrm{~min}$ (experiment 3), the solid yield dropped almost by half, even when the catalyst concentration was reduced, and the xylose concentration decreased to $1 \mathrm{~g} / \mathrm{L}$, with enhanced FF concentrations in both phases (equivalent to an overall molar conversion of $78.3 \%$ ). This finding confirmed that $\left[\mathrm{C}_{3} \mathrm{SO}_{3} \mathrm{Hmim}\right] \mathrm{HSO}_{4}$ presents a remarkable potential for obtaining $\mathrm{FF}$ from xylan-containing materials. However, the concentrations of LevA were still low (equivalent to $27.0 \%$ overall molar conversion), owing to the presence in the medium of other cellulose-derived intermediates (glucose and HMF, which were obtained at $22.2 \%$ and $10.7 \%$ overall molar yields, respectively).

In order to improve the production of LevA, additional assays were carried out at a higher temperature $\left(190^{\circ} \mathrm{C}\right)$ for 0,30 , and 50 min of isothermal operation (experiments 4, 5, and 6 in Table 1). The results obtained in experiment 4 (26.1\% solid yield, glucose concentration corresponding to $39.7 \%$ molar yield; xylose accounting for $14.9 \%$ of the stoichiometric amount) indicated that the experiment was performed under conditions too mild for practical purposes. Better results were achieved in experiment 5, with low concentrations of glucose and xylose in the aqueous phase (indicative of increased conversions into furans and/or furan-derived products), and improved concentrations of LevA and FF (which were obtained at $43.2 \%$ and $58.3 \%$ molar yields, respectively). Additionally, under these conditions, FA was obtained at $54.9 \%$ molar conversion, and acetyl groups were totally converted into AcH. Prolonging the reaction time up to $50 \mathrm{~min}$ (experiment 6) led to worse results (LevA and FF were obtained at $42.4 \%$ and $49.0 \%$ molar yields). In summary, the conditions of experiment 5 were the best ones for achieving the simultaneous conversion of hemicellulose and cellulose into FF and LevA/FA.

In the acidic processing of $\mathrm{LB}$, increasing the relative amount of liquid with respect to the solid substrate is known to improve the experimental results, because dilution limits the participation of reactive intermediates and products in parasitic reactions. Additionally, lower catalyst charges may result in improved selectivity. In order to assess these points, experiments 7, 8, and 9 were carried 
out at $180^{\circ} \mathrm{C}$ for 15,30 , or $45 \mathrm{~min}$, respectively, in media containing $0.1 \mathrm{~g}$ catalyst/g oven-dry wood. The solid yields obtained in these experiments (in the range 8.1-6.9\%) indicated that solubilization reactions affected both polysaccharides and lignin. The aqueous phase obtained in experiment 7 contained $16.9 \mathrm{~g}$ glucose/L, indicating that the severity was still not enough to achieve optimal amounts of LevA and FA (which were obtained at $13.4 \%$ and $21.2 \%$ molar conversions, respectively). In turn, these conditions were excellent for FF production, which was obtained at $89.4 \%$ molar conversion. When the reaction time was extended to $30 \mathrm{~min}$ (experiment 8), the FF generation decreased slightly (molar conversion, 87.4\%), but the LevA production increased (molar conversion, 25.3\%). Looking for an improved production of LevA/FA, the reaction was performed for 45 min (experiment 9). This modification resulted in increased FF consumption (molar yield, 80.4\%), but the production of LevA and FA improved up to $43.0 \%$ and $56.3 \%$ molar conversions, respectively.

Based on the above results, experiments 10, 11, and 12 were performed to assess the possible benefits derived from operating at a higher temperature $\left(190{ }^{\circ} \mathrm{C}\right)$ for 15,30 , or 45 min, keeping the rest of the operational variables unchanged. The limited solid yields (in the range 5.6-4.7\%) confirmed that almost total wood liquefaction took place under the considered conditions. In experiment 10 (reaction time, $15 \mathrm{~min}$ ), the most remarkable finding was the excellent conversion of precursors into FF, which was obtained at $92.6 \%$ molar yield. However, LevA and FA were obtained at 35.5\% and $48.1 \%$ molar yields, respectively. The data suggested that the results could be improved by enhancing the conversion of intermediates (glucose and HMF, which were obtained at $2.64 \%$ and $13.5 \%$ molar yields, respectively) into the target products. This idea was assessed by increasing the reaction time to $30 \mathrm{~min}$ (conditions of experiment 11). As expected, the generation of LevA and FA increased (molar yields, $44.8 \%$ and $56.8 \%$, respectively), at the cost of worsening the FF production (molar yield, $81.3 \%$ ). However, the conditions of experiment 11 can be considered as a satisfactory compromise for the one-pot production of bio-based chemicals, because harsher conditions (as the ones employed in experiment 12, in which the reaction time was fixed in $45 \mathrm{~min}$ ) resulted in a slightly improved LevA production (molar yield, 45.8\%) but in an important FF loss (molar yield, 75.8\%). 
Table 1. Operational conditions assayed and experimental results achieved in one-pot experiments using native E. globulus wood as a feedstock.

\begin{tabular}{|c|c|c|c|c|c|c|c|c|c|c|c|c|c|c|c|c|c|c|}
\hline \multirow{3}{*}{ EXPER } & \multirow{2}{*}{\multicolumn{5}{|c|}{ OPERATIONAL CONDITIONS }} & \multicolumn{13}{|c|}{ EXPERIMENTAL RESULTS } \\
\hline & & & & & & \multirow{2}{*}{ SY } & \multicolumn{7}{|c|}{ Concentrations in Aqueous Phase, $\mathrm{g} / \mathrm{L}$} & \multicolumn{5}{|c|}{ Concentrations in Organic Phase, $\mathrm{g} / \mathrm{L}$} \\
\hline & $\mathrm{CC}$ & WSR & OSR & $\mathbf{T}$ & $\mathbf{t}$ & & Glc & Xyc & FAc & $\mathrm{AcHc}$ & LevAc & HMFc & FFc & FAc & $\mathrm{AcHc}$ & LevAc & HMFc & FFc \\
\hline 1 & 0.15 & 6 & 12 & 170 & 0 & 53.7 & 12.4 & 18.6 & 2.14 & 3.02 & 0.10 & 0.20 & 0.31 & 0.10 & 1.54 & 0.05 & 0.19 & 2.14 \\
\hline 2 & 0.15 & 6 & 12 & 180 & 0 & 38.5 & 28.0 & 8.18 & 1.06 & 3.11 & 0.98 & 0.68 & 0.61 & 0.28 & 1.54 & 0.34 & 0.54 & 3.52 \\
\hline 3 & 0.10 & 6 & 12 & 180 & 16 & 19.5 & 17.9 & 1.00 & 3.96 & 3.11 & 6.54 & 1.71 & 0.66 & 1.64 & 1.57 & 3.26 & 1.84 & 5.73 \\
\hline 4 & 0.15 & 6 & 12 & 190 & 0 & 26.1 & 32.2 & 4.38 & 1.44 & 3.07 & 2.99 & 1.17 & 0.74 & 0.59 & 1.55 & 0.88 & 0.85 & 4.12 \\
\hline 5 & 0.15 & 6 & 12 & 190 & 30 & 18.1 & 0.16 & 0.17 & 5.74 & 3.50 & 10.4 & 0.04 & 0.52 & 2.44 & 1.77 & 5.27 & 0.04 & 4.25 \\
\hline 6 & 0.15 & 6 & 12 & 190 & 50 & 17.9 & 0.17 & 0.20 & 5.40 & 3.41 & 10.1 & $<0.01$ & 0.42 & 2.27 & 1.73 & 5.15 & $<0.01$ & 3.58 \\
\hline 7 & 0.10 & 10 & 20 & 180 & 15 & 8.10 & 16.9 & 1.16 & 1.27 & 1.95 & 1.95 & 2.11 & 0.43 & 0.58 & 0.99 & 0.95 & 2.30 & 3.89 \\
\hline 8 & 0.10 & 10 & 20 & 180 & 30 & 8.00 & 9.14 & 0.60 & 2.25 & 2.10 & 3.58 & 1.81 & 0.39 & 0.86 & 1.06 & 1.83 & 2.07 & 3.82 \\
\hline 9 & 0.10 & 10 & 20 & 180 & 45 & 6.90 & 1.00 & 0.29 & 3.55 & 2.17 & 6.08 & 0.62 & 0.40 & 1.46 & 1.11 & 3.13 & 0.69 & 3.49 \\
\hline 10 & 0.10 & 10 & 20 & 190 & 15 & 5.60 & 1.26 & $\begin{array}{l}0.32 \\
4.70\end{array}$ & 2.99 & 2.15 & 4.97 & 1.24 & 0.44 & 1.26 & 1.08 & 2.59 & 1.41 & 4.03 \\
\hline 11 & 0.10 & 10 & 20 & 190 & 30 & 5.43 & 0.16 & 0.26 & 3.61 & 2.35 & 6.27 & 0.17 & 0.35 & 1.47 & 1.20 & 3.28 & 0.22 & 3.56 \\
\hline 12 & 0.10 & 10 & 20 & 190 & 45 & 4.69 & 0.14 & 0.29 & 3.58 & 2.31 & 6.44 & 0.03 & 0.35 & 1.53 & 1.17 & 3.34 & 0.03 & 3.30 \\
\hline
\end{tabular}

Nomenclature: CC, catalyst concentration in g catalyst/g feedstock; WSR, water-to-solid ratio in g aqueous phase/g feedstock; OSR, organic solvent-to-solid ratio in $\mathrm{g}$ methyl isobutyl ketone $(\mathrm{MIBK}) / \mathrm{g}$ feedstock; $\mathrm{T}$, temperature in ${ }^{\circ} \mathrm{C}$; $\mathrm{t}$, isothermal reaction time in min; SY, solid yield in g solid after treatment/g feedstock; Glc, glucose concentration in g/L, Xyc, xylose concentration in $\mathrm{g} / \mathrm{L} ; \mathrm{FAc}$ formic acid concentration in $\mathrm{g} / \mathrm{L} ; \mathrm{AcHc}$, acetic acid concentration in $\mathrm{g} / \mathrm{L} ;$ Lev Ac, levulinic acid concentration in $\mathrm{g} / \mathrm{L} ; \mathrm{HMFc}$, HMF concentration in $\mathrm{g} / \mathrm{L} ; \mathrm{FFc}$, furfural concentration in $\mathrm{g} / \mathrm{L}$. 


\subsection{Eucalyptus Globulus Wood Conversion Based on Hemicellulose Removal}

\subsubsection{Hydrothermal Processing}

Figure $1 \mathrm{~b}$ shows the general idea of a biorefinery process based on hydrothermal processing (also named autohydrolysis) and further individual utilization of the liquid phase (containing soluble hemicellulose-derived saccharides) and the solid phase (containing cellulose and lignin). The autohydrolysis of Eucalyptus globulus wood has been considered in the literature [39], and it is considered as a green, efficient, and selective method for hemicellulose separation from cellulose and lignin. Operating under suitable conditions, the major soluble reaction products are hemicellulose-derived saccharides (mainly of oligomeric nature), which are accompanied by minor amounts of sugars and sugar-dehydration products. The saccharides present in the aqueous phase are substrates suitable for FF manufacture [32], whereas lignin and cellulose undergo little modification and remain in solid phase, enabling their separate utilization. In this work, the treatments were performed using a water-to-solid ratio of $8 \mathrm{~kg} / \mathrm{kg}$. The media were heated up to reach $200{ }^{\circ} \mathrm{C}$ and cooled immediately, following the temperature profiles reported in Garrote and Parajó [39]. Upon hydrothermal processing, 28.9\% of the wood mass was solubilized, yielding a treated solid enriched in cellulose, and a liquid phase containing xylooligomers as major products. Table 2 lists the composition of both phases.

Table 2. Composition of solid and liquid phases from hydrothermal processing.

\begin{tabular}{cc}
\hline & (a) Solid Phase \\
\hline COMPONENT & CONTENT (g/100 g Treated Solid, Oven-Dry Basis) \\
\hline Cellulose & 58.8 \\
Xylan & 3.20 \\
Arabinan & 0.07 \\
Acetyl groups & 0.69 \\
Klason lignin & 30.6 \\
\hline & (b) Liquid Phase \\
\hline COMPONENT & CONCENTRATION (g/L) \\
\hline Glucose & 0.51 \\
Xylose & 6.40 \\
Arabinose & 0.51 \\
FA & 0.66 \\
AcH & 1.41 \\
LevA & 0.02 \\
HMF & 0.09 \\
FF & 0.57 \\
\hline Arabinosyl groups in oligomers & 1.00 \\
Acetyl groups in oligomers & 12.9 \\
Arosyl groups in oligomers & 0.00 \\
\hline & 3.32 \\
\hline
\end{tabular}

\subsubsection{Conversion of the Solids from Hydrothermal Processing}

Based on the above information, the cellulose-enriched solids coming from hydrothermal fractionation (see Figure $1 \mathrm{~b}$ ), mainly made up of cellulose $(58.8 \%)$ and lignin $(30.6 \%)$, were treated with water, $\left[\mathrm{C}_{3} \mathrm{SO}_{3} \mathrm{Hmim}\right] \mathrm{HSO}_{4}$, and $\mathrm{MIBK}$ to yield $\mathrm{HMF}$, LevA, and FA. Owing to the limited xylan and arabinan contents of the treated solids (3.20 and $0.07 \%$, respectively), the generation of FF is not discussed in this section.

The experimental plan was established keeping in mind the results obtained in assays 7 to 12 in Table 1 . Those assays were performed at 180 or $190^{\circ} \mathrm{C}$ with a catalyst concentration (denoted CC) of $0.1 \mathrm{~g}$ catalyst/g oven-dry wood, for reaction times $(\mathrm{t})$ up to $45 \mathrm{~min}$. Table 3 lists the operational conditions assayed in this part of our study (similar to the above ones, except the longest reaction time, 
which was fixed in 75 or $60 \mathrm{~min}$ for operation at 180 or $190^{\circ} \mathrm{C}$, respectively). The same table includes the volumetric concentrations of the target products in the aqueous and organic phases. For clarity, Figure 2; Figure 3 show the experimental results in terms of overall molar conversions (including the amounts of the target products contained in both the aqueous and organic phases).

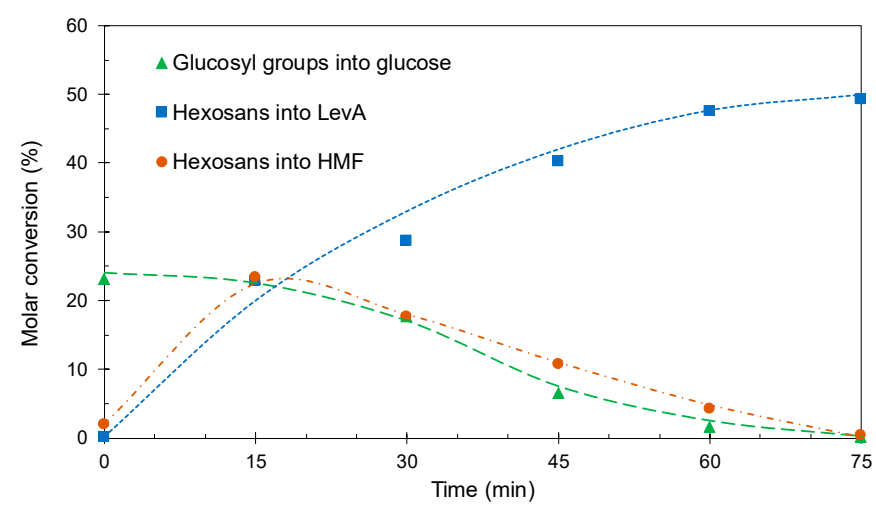

Figure 2. Overall molar conversions (including the contributions of aqueous and organic phases) achieved in experiments performed at $180{ }^{\circ} \mathrm{C}$ using the solids from hydrothermal processing as a substrate and $\left[\mathrm{C}_{3} \mathrm{SO}_{3} \mathrm{Hmim}\right] \mathrm{HSO}_{4}$ as a catalyst.

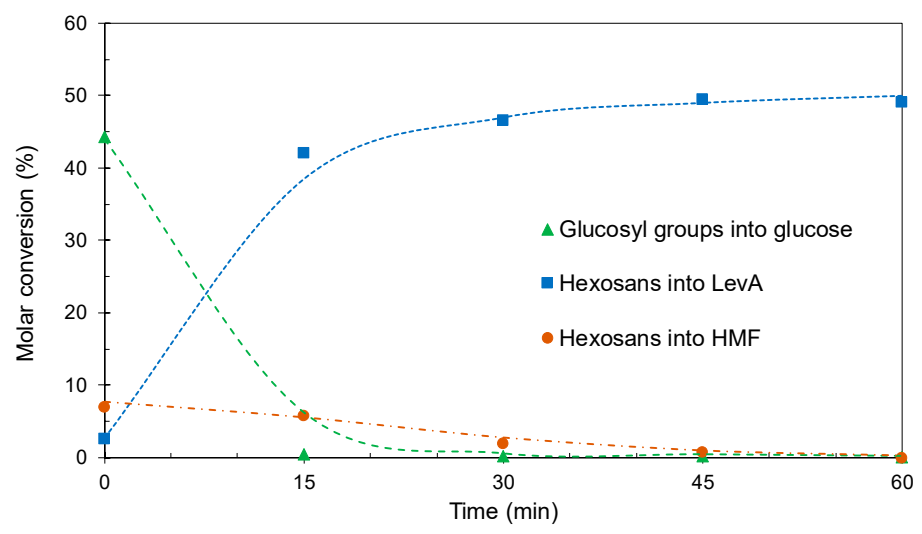

Figure 3. Overall molar conversions (including the contributions of aqueous and organic phases) achieved in experiments performed at $190{ }^{\circ} \mathrm{C}$ using the solids from hydrothermal processing as a substrate and $\left[\mathrm{C}_{3} \mathrm{SO}_{3} \mathrm{Hmim}\right] \mathrm{HSO}_{4}$ as a catalyst.

The high solid yield and glucose concentration in aqueous phase obtained in experiment 1 , which was performed at $180{ }^{\circ} \mathrm{C}$ with no isothermal stage (see Table 3), resulted in incomplete cellulose conversion, indicating that the conditions were too mild for the purposes of this study. Implementing an isothermal stage of 15-75 min (experiments 2-6 in Table 3) substantially decreased the solid yield to 15.3-13.4 g/100 g solid and caused a steady increase in the concentrations of LevA and FA. The effects of the reaction time on the cellulose conversion into glucose, HMF, and LevA are displayed in Figure 2, where it can be seen that glucose and HMF behaved as reaction intermediates, whereas the maximum LevA molar conversion (49.3\%) was reached after $75 \mathrm{~min}$. 
Table 3. Operational conditions assayed and experimental results achieved in the conversion of the solids from hydrothermal processing.

\begin{tabular}{|c|c|c|c|c|c|c|c|c|c|c|c|c|c|}
\hline \multirow{3}{*}{ EXPER } & \multirow{2}{*}{\multicolumn{5}{|c|}{ OPERATIONAL CONDITIONS }} & \multicolumn{8}{|c|}{ EXPERIMENTAL RESULTS } \\
\hline & & & & & & \multirow{2}{*}{ SY } & \multicolumn{4}{|c|}{ Concentrations in Aqueous Phase, $\mathrm{g} / \mathrm{L}$} & \multicolumn{3}{|c|}{ Concentrations in Organic Phase, $\mathrm{g} / \mathrm{I}$} \\
\hline & $\mathrm{CC}$ & WSR & OSR & $\mathbf{T}$ & $\mathbf{t}$ & & Glc & FAc & LevAc & HMFc & FAc & LevAc & HMFc \\
\hline 1 & 0.1 & 10 & 20 & 180 & 0 & 61.7 & 14.9 & 0.17 & 0.03 & 0.25 & 0.03 & 0.02 & 0.27 \\
\hline 2 & 0.1 & 10 & 20 & 180 & 15 & 15.0 & 14.8 & 2.45 & 4.18 & 2.64 & 0.95 & 2.09 & 3.13 \\
\hline 3 & 0.1 & 10 & 20 & 180 & 30 & 15.3 & 11.2 & 2.93 & 5.23 & 2.18 & 1.20 & 2.62 & 2.29 \\
\hline 4 & 0.1 & 10 & 20 & 180 & 45 & 14.8 & 4.16 & 4.04 & 7.38 & 1.32 & 1.60 & 3.65 & 1.41 \\
\hline 5 & 0.1 & 10 & 20 & 180 & 60 & 15.2 & 1.10 & 4.51 & 8.69 & 0.52 & 1.86 & 4.34 & 0.58 \\
\hline 6 & 0.1 & 10 & 20 & 180 & 75 & 13.4 & 0.15 & 4.62 & 8.98 & 0.06 & 1.89 & 4.50 & 0.06 \\
\hline 7 & 0.1 & 10 & 20 & 190 & 0 & 42.0 & 28.4 & 0.45 & 0.60 & 0.91 & 0.11 & 0.21 & 0.90 \\
\hline 8 & 0.1 & 10 & 20 & 190 & 15 & 22.0 & 0.35 & 4.32 & 7.66 & 0.68 & 1.72 & 3.85 & 0.76 \\
\hline 9 & 0.1 & 10 & 20 & 190 & 30 & 21.9 & 0.19 & 4.54 & 8.41 & 0.23 & 1.82 & 4.31 & 0.27 \\
\hline 10 & 0.1 & 10 & 20 & 190 & 45 & 13.2 & 0.16 & 4.72 & 8.94 & 0.09 & 1.95 & 4.54 & 0.10 \\
\hline 11 & 0.1 & 10 & 20 & 190 & 60 & 12.0 & 0.12 & 4.55 & 8.82 & $<0.01$ & 1.83 & 4.45 & $<0.01$ \\
\hline
\end{tabular}

Nomenclature: CC, catalyst concentration in g catalyst/g feedstock; WSR, water-to-solid ratio in g aqueous phase/g feedstock; OSR, organic solvent-to-solid ratio in g MIBK/g feedstock; T temperature in ${ }^{\circ} \mathrm{C}$; $\mathrm{t}$, isothermal reaction time in min; SY, solid yield in $\mathrm{g}$ solid after treatment/g feedstock; Glc, glucose concentration in $\mathrm{g} / \mathrm{L}$, Xyc, xylose concentration in $\mathrm{g} / \mathrm{L} ; \mathrm{FAc}$ formic acid concentration in $\mathrm{g} / \mathrm{L} ; \mathrm{AcHc}$, acetic acid concentration in $\mathrm{g} / \mathrm{L}$; Lev Ac, levulinic acid concentration in $\mathrm{g} / \mathrm{L} ; \mathrm{HMFc}$, HMF concentration in $\mathrm{g} / \mathrm{L} ; \mathrm{FFc}$, furfural concentration in $\mathrm{g} / \mathrm{L}$. 
The effects caused by increasing the temperature up to $190{ }^{\circ} \mathrm{C}$ (keeping constant the rest of operational variables) were considered in experiments 7 to 11 in Table 3 . As before, high solid yields and low concentrations of intermediates and target products were obtained when no isothermal reaction stage was considered (experiment 7). Increasing the reaction time up to $60 \mathrm{~min}$ (experiments 8 to 11) resulted in a fast increase of the concentrations of the target products. Figure 3, which presents the results in terms of molar conversions, shows a fast consumption of intermediates and a maximum molar conversion into LevA of $49.5 \%$ (the highest value reached in this study).

\subsubsection{Conversion of the Liquid Phase from Hydrothermal Processing}

The liquid phase from hydrothermal processing (see Figure 1b), with the composition indicated in Table 2, was supplemented with $\left[\mathrm{C}_{3} \mathrm{SO}_{3} \mathrm{Hmim}\right] \mathrm{HSO}_{4}$ and heated in the presence of MIBK to produce FF from the suitable precursors. The optimization of FF manufacture was studied using the Response Surface Methodology, based on a factorial, incomplete, and centered Box-Behnken experimental design, in which three selected independent variables $(\mathrm{T}, \mathrm{t}$, and the volumetric catalyst concentration, denoted VCC) were assayed in duplicate at three levels. The ranges considered for the operational variables were $160-180^{\circ} \mathrm{C}$ for temperature and 2-30 min for $\mathrm{t}$; whereas VCC varied from $1.42 \times 10^{-2}$ up to $4.26 \times 10^{-2} \mathrm{~g} / \mathrm{g}$ aqueous phase. As before, the MIBK/aqueous phase mass ratio was fixed in 2 $\mathrm{g} / \mathrm{g}$. The only dependent variable considered in this part of the study was the FF molar yield (denoted FFMY), which was measured in respect to the potential substrates in the liquid phase.

The operational conditions employed in diverse experiments and the corresponding FFMY values are listed in Table 4.

Table 4. Operational conditions employed in experiments of furfural (FF) production from hemicellulose-derived saccharides, and experimental results obtained for the furfural molar yield. FFMY: FF molar yield, VCC: volumetric catalyst concentration.

\begin{tabular}{ccccc}
\hline Exper. & $\mathbf{T}^{\circ}{ }^{\circ} \mathbf{C}$ & T, min & VCC, g/g Aqueous Phase & FFMY, $\%$ \\
\hline $1 \mathrm{a}$ & 170 & 16 & $2.84 \times 10^{-2}$ & 77.6 \\
$1 \mathrm{~b}$ & 170 & 16 & $2.84 \times 10^{-2}$ & 77.0 \\
$2 \mathrm{a}$ & 160 & 30 & $2.84 \times 10^{-2}$ & 75.6 \\
$2 \mathrm{~b}$ & 160 & 30 & $2.84 \times 10^{-2}$ & 75.4 \\
$3 \mathrm{a}$ & 180 & 16 & $1.42 \times 10^{-2}$ & 78.7 \\
$3 \mathrm{~b}$ & 180 & 16 & $1.42 \times 10^{-2}$ & 76.3 \\
$4 \mathrm{a}$ & 170 & 2 & $4.26 \times 10^{-2}$ & 73.8 \\
$4 \mathrm{~b}$ & 170 & 2 & $4.26 \times 10^{-2}$ & 73.4 \\
$5 \mathrm{a}$ & 160 & 16 & $1.42 \times 10^{-2}$ & 51.0 \\
$5 \mathrm{~b}$ & 160 & 16 & $1.42 \times 10^{-2}$ & 53.3 \\
$6 \mathrm{a}$ & 170 & 30 & $1.42 \times 10^{-2}$ & 77.3 \\
$6 \mathrm{~b}$ & 170 & 30 & $1.42 \times 10^{-2}$ & 80.3 \\
$7 \mathrm{a}$ & 160 & 16 & $4.26 \times 10^{-2}$ & 70.7 \\
$7 \mathrm{~b}$ & 160 & 16 & $4.26 \times 10^{-2}$ & 74.3 \\
$8 \mathrm{a}$ & 180 & 2 & $2.84 \times 10^{-2}$ & 77.0 \\
$8 \mathrm{~b}$ & 180 & 2 & $2.84 \times 10^{-2}$ & 79.4 \\
$9 \mathrm{a}$ & 180 & 16 & $4.26 \times 10^{-2}$ & 72.0 \\
$9 \mathrm{~b}$ & 180 & 16 & $4.26 \times 10^{-2}$ & 70.9 \\
$10 \mathrm{a}$ & 170 & 2 & $1.42 \times 10^{-2}$ & 45.5 \\
$10 \mathrm{~b}$ & 170 & 2 & $1.42 \times 10^{-2}$ & 44.3 \\
$11 \mathrm{a}$ & 160 & 2 & $2.84 \times 10^{-2}$ & 43.4 \\
$11 \mathrm{~b}$ & 160 & 2 & $2.84 \times 10^{-2}$ & 37.8 \\
$12 \mathrm{a}$ & 180 & 30 & $2.84 \times 10^{-2}$ & 72.3 \\
$12 \mathrm{~b}$ & 180 & 30 & $2.84 \times 10^{-2}$ & 72.7 \\
$13 \mathrm{a}$ & 170 & 30 & $4.26 \times 10^{-2}$ & \\
$13 \mathrm{~b}$ & 170 & 30 & $4.26 \times 10^{-2}$ & \\
\hline
\end{tabular}


For calculation purposes, the following normalized, dimensionless variables with variation ranges $(-1,1)$ were defined:

$$
\begin{gathered}
\left.\mathrm{x}_{1} \text { (dimensionless temperature for experiment } \mathrm{j}\right)=2 \cdot\left(\mathrm{T}_{\mathrm{j}}-170\right) /(180-160) \\
\mathrm{x}_{2}(\text { dimensionless time for experiment } \mathrm{j})=2 \cdot\left(\mathrm{t}_{\mathrm{j}}-16\right) /(30-2) \\
\mathrm{x}_{3}(\text { dimensionless volumetric catalyst concentration for experiment } \mathrm{j})= \\
2 \cdot\left(\mathrm{VCC}_{\mathrm{j}}-2.84 \times 10^{-2}\right) /\left(4.26 \times 10^{-2}-1.42 \times 10^{-2}\right)
\end{gathered}
$$

The values of the FFMY data in Table 4 were correlated with the values of the correspondent normalized variables using the following second-order equation involving linear, interaction, and quadratic terms.

$$
F F M Y=a_{0}+a_{1} \cdot x_{1}+a_{2} \cdot x_{2}+a_{3} \cdot x_{3}+a_{12} \cdot x_{1} \cdot x_{2}+a_{13} \cdot x_{1} \cdot x_{3}+a_{23} \cdot x_{2} \cdot x_{3}+a_{11} \cdot x_{1}{ }^{2}+a_{22} \cdot x_{2}{ }^{2}+a_{33} \cdot x_{3}{ }^{2}
$$

Table 5 lists the values of the regression coefficients (calculated by the least squares method), their statistical significance (based on a $t$-test), the statistical significance of the model (measured using the $\mathrm{F}_{\mathrm{st}}$ Fischer's test), and the correlation coefficient.

Table 5. Regression coefficients, statistical significance (based on a $t$-test), and parameters measuring the correlation and significance of the statistical model.

\begin{tabular}{ccc}
\hline Coefficient & Value & Statistical Significance \\
\hline $\mathrm{a}_{0}$ & 77.30 & $>99 \%$ \\
$\mathrm{a}_{1}$ & 7.36 & $>99 \%$ \\
$\mathrm{a}_{2}$ & 7.77 & $>99 \%$ \\
$\mathrm{a}_{3}$ & 4.59 & $>99 \%$ \\
$\mathrm{a}_{12}$ & -10.15 & $>99 \%$ \\
$\mathrm{a}_{13}$ & -6.59 & $>99 \%$ \\
$\mathrm{a}_{23}$ & -8.74 & $>99 \%$ \\
$\mathrm{a}_{11}$ & -4.84 & $>99 \%$ \\
$\mathrm{a}_{22}$ & -5.76 & $>99 \%$ \\
$\mathrm{a}_{33}$ & -4.08 & $>99 \%$ \\
\hline \multicolumn{2}{c}{ Statistical parameters: $\mathrm{R}^{2}: 0.980 ; F_{s t}: 87.3$ (significance $\left.>99 \%\right)$}
\end{tabular}

The model predictions were analyzed on the basis of the response surfaces shown in Figure 4; Figure 5. Figure 4 shows that at $170{ }^{\circ} \mathrm{C}$, the FFMY was favored by operation at long reaction times with limited catalyst charges, with a clearly defined optimum zone. Figure 5 depicts a closely related situation: in assays lasting $16 \mathrm{~min}$, the best results were predicted for low or intermediate catalyst loadings, with a defined optimum zone appearing near the highest temperature assayed. 


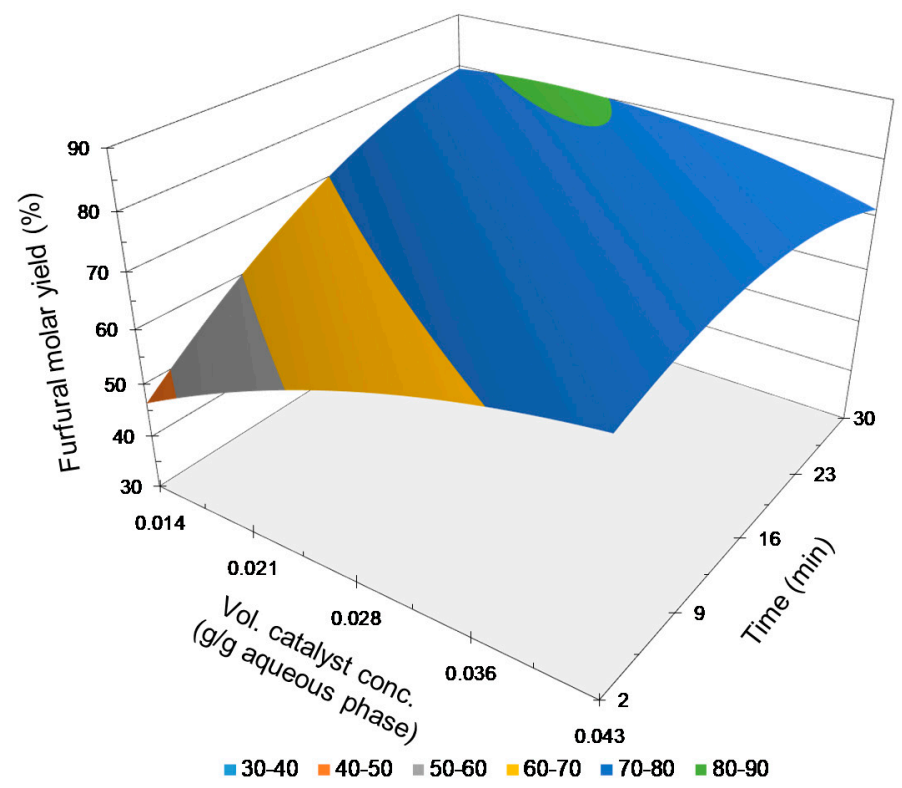

Figure 4. Dependence of the furfural molar conversion on time and volumetric catalyst concentration (data calculated for $\mathrm{T}=170^{\circ} \mathrm{C}$ ).

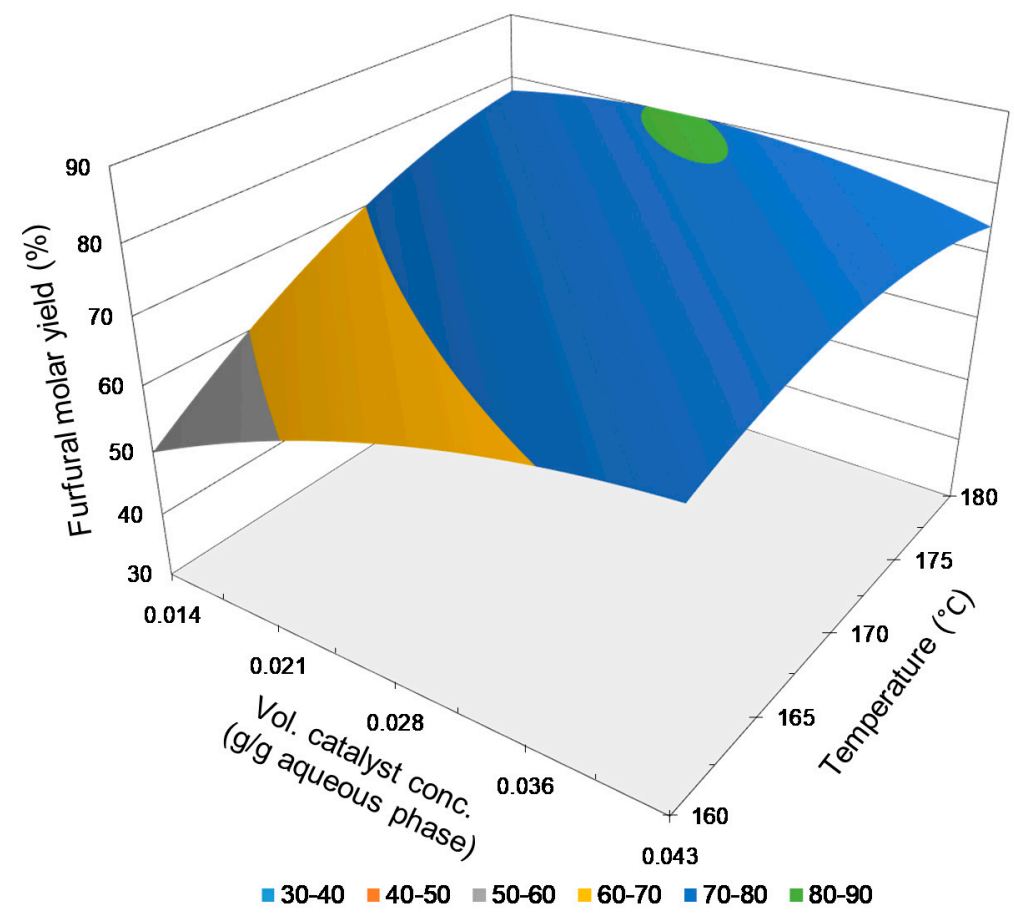

Figure 5. Dependence of the furfural molar conversion on temperature and volumetric catalyst concentration (data calculated for $\mathrm{t}=16 \mathrm{~min}$ ).

The mathematical optimization of the statistical model within the experimental domain $\left(\partial \mathrm{FFMY} / \partial \mathrm{x}_{\mathrm{i}}\right.$ $=0 ;-1 \leq \mathrm{x}_{\mathrm{i}} \leq 1$; i: 1 to 3 ) was predicted a maximum FFMY $(80.4 \%)$ for $\mathrm{T}=171^{\circ} \mathrm{C}, \mathrm{t}=30 \mathrm{~min}$, and VCC $=1.97 \times 10^{-2} \mathrm{~g}$ catalyst $/ \mathrm{g}$ aqueous phase. Additional experiments performed for model validation led to an FFMY near 78\%, which was close to the experimental results obtained in experiments 3, 6, and 8 , and it defined a region of the experimental domain where the experimental and fitting errors overlapped the possible differences in FFMY values. 


\subsubsection{Comparative Analysis of Results}

The literature has considered the utilization of AIL as reaction media and/or as catalysts for obtaining platform chemicals from a number of substrates, including sugars, hemicellulose-derived saccharides, purified polysacharides, LB-derived fractions, and native LB. However, comparing the results reported with the ones achieved in this study is not straightforward, owing to important differences in the types of substrates and catalysts, the diversity of operational conditions (particularly, regarding catalyst and substrate charges), and the type of target products (FF and/or HMF and/or LevA+FA).

Concerning the FF production from wood hemicellulose (with or without the simultaneous production of LevA from cellulose), Zhang and Zhao [40] treated wood in 1-butyl-3-methylimidazolium chloride catalyzed with $\mathrm{CrCl}_{3}$ to obtain $\mathrm{FF}$ at yields up to $31 \%$, together with $\mathrm{HMF}$. The same IL was employed by Sievers et al. [41] to obtain HMF and FF (at low mass yield) from loblolly pine using trifluoroacetic acid as a catalyst. López et al. [38] employed 1-butyl-3-methylimidazolium hydrogen sulfate as a catalyst to achieve $60.5 \%$ conversion of pine wood pentosans into FF. Under the considered operational conditions, little conversion of cellulose into LevA was achieved, which is ascribed to the limited acidity of the catalyst. $\left[\mathrm{C}_{3} \mathrm{SO}_{3} \mathrm{Hmim}\right] \mathrm{HSO}_{4}$ and $\left[\mathrm{C}^{2} \mathrm{SO}_{3} \mathrm{Hmim}\right] \mathrm{HSO}_{4}$, two AIL of enhanced acidity (caused by the sulfonic group attached to the cation) have been successfully employed for processing purified cellulose and native LB. A near-quantitative conversion of xylosyl and arabinosyl groups in native pine wood into FF was achieved using these catalysts [38]. Concerning the production of LevA, 39.4-55\% molar conversion was reached using microcrystalline cellulose as a substrate [26], [37], or 32.8\% molar conversion of precursos (hexosans) in pine wood [38]. Obtaining higher LevA yields entailed the utilization of high catalyst charges (up to $4 \mathrm{~g} / \mathrm{g}$ cellulose) [29], whereas the manufacture of soluble products from LB was favored when susceptible substrates of low lignin content (such as bagasse) were employed [42].

Regarding the FF production from LB-derived fractions, Peleteiro et al. [32] employed the liquid phase from Eucalyptus globulus wood autohydrolysis (containing xylooligosaccharides as major reaction products) as a substrate for reaction in biphasic media catalyzed with 1-butyl-3-methylimidazolium hydrogen sulfate. MIBK and toluene were employed as organic solvents, at a 4.4/1 mass ratio with respect to the aqueous phase, which was concentrated using membranes before reaction. Under the best operational conditions, the molar conversion of the suitable precursors into FF reached $68.4 \%$. In a related study, a biorefinery solution enriched in $\mathrm{C} 5$ oligomers coming from the aqueous processing of agricultural LB was treated in a biphasic media (water/tetrahydrofuran) in the presence of the AIL 1-(4-sulfonylbutyl)pyridinium methanesulfonate, yielding FF at molar conversions up to $45 \%$ [34].

\section{Materials and Methods}

\subsection{Raw Material}

Eucalyptus globulus wood chips were collected in a local pulp mill, milled to pass an $8 \mathrm{~mm}$ screen, air-dried to a final moisture of $6.6 \%$, and employed for reaction. The wood samples employed for analysis were further milled and screened following the NREL/TP-510-42620 standard method.

\subsection{Reaction}

In hydrothermal reactions, wood samples were mixed with water at the desired solid charge (8 $\mathrm{kg}$ liquid phase $/ \mathrm{kg}$ oven-dry wood) and heated up to $200^{\circ} \mathrm{C}$ in a $3.75 \mathrm{~L}$ stainless steel, stirred Parr reactor (Parr Instruments, Moline, Illinois, USA). In one-pot reactions, wood was mixed with water, [C3SO3Hmim]HSO4 (purchased from Ionic Liquids Technologies $\mathrm{GmbH}$, Heilbronn, Germany) and MIBK, and reacted for the desired time at the target temperature and solid charge (see text and table headings for specific information) using a stirred MARS 6 MW reactor. Reactions involving the liquid phase from hydrothermal processing were carried out in the presence of $\left[\mathrm{C}_{3} \mathrm{SO}_{3} \mathrm{Hmim}\right] \mathrm{HSO}_{4}$ and 
MIBK using the same MW reactor, under the set of experimental conditions indicated in the Results section. All reaction conditions were assayed in duplicate experiments.

\subsection{Analysis}

Wood samples were assayed for polysaccharides (cellulose and hemicelluloses) and lignin by quantitative acid hydrolysis (NREL standard method/TP-510-42618). The target products in liquid phase (oligosaccharides, sugars, furans, and organic acids) coming from quantitative acid hydrolysis or reaction experiments were determined by HPLC-IR and HPLC-Diode Array Detector as per Rivas et al. [43].

\section{Conclusions}

The acidic ionic liquid $\left[\mathrm{C}_{3} \mathrm{SO}_{3} \mathrm{Hmim}\right] \mathrm{HSO}_{4}$ was employed as a catalyst for Eucalyptus globulus wood processing in reaction media also containing water and wood (or wood-derived fractions). Operating in the presence of MIBK, two different operational modes were considered (see Figure 1): (a) one-pot reaction and (b) the separate conversion of hemicellulose-derived products and cellulose-enriched solids resulting from hydrothermal fractionation.

Following the one-pot approach, mild reaction conditions $\left(170^{\circ} \mathrm{C}, 0 \mathrm{~min}\right.$ of isothermal reaction time, $0.15 \mathrm{~g}$ catalyst/g oven-dry wood) resulted in the hydrolysis of xylan into xylose at $62.8 \%$ molar conversion. Harsher conditions increased the formation of FF (up to 92.6\% molar conversion) and levulinic acid (up to $45.8 \%$ molar conversion). Conditions of increased severity $\left(190{ }^{\circ} \mathrm{C}, 30 \mathrm{~min}, 0.10\right.$ g catalyst/g oven-dry wood) resulted in slightly decreased FF production ( $81.3 \%$ molar conversion) but a better conversion of cellulose into LevA (44.8\%). Concerning the separate conversion of the phases resulting from hydrothermal processing, the conversion of the cellulose-enriched solid into LevA under optimal conditions $\left(190^{\circ} \mathrm{C}, 45 \mathrm{~min}, 0.10 \mathrm{~g}\right.$ catalyst/g oven-dry wood) proceeded at about $49.5 \%$ molar conversion, whereas the hemicellulose-derived saccharides present in the liquid phase yielded FF at near $78 \%$ molar conversion.

The experimental results confirm the suitability of $\left[\mathrm{C}_{3} \mathrm{SO}_{3} \mathrm{Hmim}\right] \mathrm{HSO}_{4}$ as a versatile catalyst for the environmentally friendly production of bio-based chemicals from the polysaccharide fraction of Eucalyptus globulus wood.

Author Contributions: Conceptualization, M.L., S.R., C.V., V.S. and J.C.P.; methodology, M.L., S.R., C.V., V.S. and J.C.P.; validation, M.L.; investigation, M.L., S.R., C.V., V.S. and J.C.P.; resources, V.S., J.C.P.; data curation, M.L.; writing - original draft preparation, M.L., S.R., C.V., V.S. and J.C.P.; writing-review and editing, M.L., V.S. and J.C.P.; supervision, V.S. and J.C.P.; project administration, V.S. and J.C.P.; funding acquisition, V.S. and J.C.P. All authors have read and agreed to the published version of the manuscript.

Funding: This research was funded by the "Ministry of Economy and Competitiveness" of Spain (research project “Modified aqueous media for wood biorefineries", reference CTQ2017-82962-R).

Acknowledgments: M.L. thanks "Xunta de Galicia" and the European Union (European Social Fund-ESF) for her predoctoral grant (reference ED481A-2017/316). S.R. thanks "Ministerio de Ciencia, Innovación y Universidades" for her "Juan de la Cierva" contract IJC2018-037665-I.

Conflicts of Interest: The authors declare no conflict of interest.

\section{References}

1. Mika, L.T.; Cséfalvay, E.; Németh, Á. Catalytic Conversion of Carbohydrates to Initial Platform Chemicals: Chemistry and Sustainability. Chem. Rev. 2018, 118, 505-613. [CrossRef] [PubMed]

2. Oak Ridge National Laboratory. U.S.; Department of Energy. U.S. Billion-Ton Update: Biomass Supply for a Bioenergy and Bioproducts Industry. 2011. Available online: https://www1.eere.energy.gov/bioenergy/pdfs/ billion_ton_update.pdf (accessed on 20 July 2020).

3. Pereira, J.S.; Linder, S.; Araujo, M.C.; Pereira, H.; Ericsson, T.; Borralho, N.; Leal, L.C. Optimization of Biomass Production in Eucalyptus Globulus Plantations-A Case Study. In Biomass Production by Fast-Growing Trees, 1st ed.; Pereira, J.S., Landsberg, J.J., Eds.; Springer: Dordrecht, The Netherlands, 1989; Volume 166, pp. 101-121. [CrossRef] 
4. Penín, L.; López, M.; Santos, V.; Alonso, J.L.; Parajó, J.C. Technologies for Eucalyptus wood processing in the scope of biorefineries: A comprehensive review. Bioresour. Technol. 2020, 311, 123528. [CrossRef] [PubMed]

5. Rockwood, D.L.; Rudie, A.W.; Ralph, S.A.; Zhu, J.Y.; Winandy, J.E. Energy product options for Eucalyptus species grown as short rotation woody crops. Int. J. Mol. Sci. 2008, 9, 1361-1378. [CrossRef] [PubMed]

6. FAO. Planted Forests and Trees Working Paper FP38E. Global Planted Forests Thematic Study: Results and Analysis 2006. Available online: http://www.fao.org/forestry/12139-03441d093f070ea7d7c4e3ec3f306507.pdf (accessed on 20 July 2020).

7. Chandel, A.K.; Garlapati, V.K.; Singh, A.K.; Antunes, F.A.F.; da Silva, S.S. The path forward for lignocellulose biorefineries: Bottlenecks, solutions, and perspective on commercialization. Bioresour. Technol. 2018, 264, 370-381. [CrossRef]

8. Naidu, D.S.; Hlangothi, S.P.; John, M.J. Bio-based products from xylan: A review. Carbohydr. Polym. 2018, 179, 28-41. [CrossRef]

9. Peleteiro, S.; Rivas, S.; Alonso, J.L.; Santos, V.; Parajó, J.C. Furfural production using ionic liquids: A review. Bioresour. Technol. 2016, 202, 181-191. [CrossRef]

10. Cai, C.M.; Zhang, T.; Kumar, R.; Wyman, C.E. Integrated furfural production as a renewable fuel and chemical platform from lignocellulosic biomass. J. Chem. Technol. Biotechnol. 2014, 89, 2-10. [CrossRef]

11. Bohre, A.; Dutta, S.; Saha, B.; Abu-Omar, M.M. Upgrading furfurals to drop-in biofuels: An overview. ACS Sustainable Chem. Eng. 2015, 3, 1263-1277. [CrossRef]

12. Frankiewicz, A. Overview of 4-oxopentanoic (levulinic) acid production methods-An intermediate in the biorefinery process. CHEMIK 2016, 70, 203-208.

13. Kang, S.; Fu, J.; Zhang, G. From lignocellulosic biomass to levulinic acid: A review on acid-catalyzed hydrolysis. Renew. Sustain. Energy Rev. 2018, 94, 340-362. [CrossRef]

14. Pileidis, F.D.; Titirici, M.M. Levulinic acid biorefineries: New challenges for efficient utilization of biomass. ChemSusChem 2016, 9, 562-582. [CrossRef] [PubMed]

15. Aslam, N.M.; Masdar, M.S.; Kamarudin, S.K.; Daud, W.R.W. Overview on Direct Formic Acid Fuel Cells (DFAFCs) as an energy sources. APCBEE Proc. 2012, 3, 33-39. [CrossRef]

16. Badgujar, K.C.; Wilson, L.D.; Bhanage, B.M. Recent advances for sustainable production of levulinic acid in ionic liquids from biomass: Current scenario, opportunities and challenges. Renew. Sustain. Energy Rev. 2019, 102, 266-284. [CrossRef]

17. Penín, L.; Peleteiro, S.; Rivas, S.; Santos, V.; Parajó, J.C. Production of 5-hydroxymethylfurfural from pine wood via biorefinery technologies based on fractionation and reaction in ionic liquids. BioResources 2019, 14, 4733-4747.

18. Sweygers, N.; Harrer, J.; Dewil, R.; Appels, L. A microwave-assisted process for the in-situ production of 5-hydroxymethylfurfural and furfural from lignocellulosic polysaccharides in a biphasic reaction system. J. Cleaner Prod. 2018, 187, 1014-1024. [CrossRef]

19. Cai, C.M.; Zhang, T.; Kumar, R.; Wyman, C.E. THF co-solvent enhances hydrocarbon fuel precursor yields from lignocellulosic biomass. Green Chem. 2013, 15, 3140-3145. [CrossRef]

20. Climent, M.J.; Corma, A.; Iborra, S. Converting carbohydrates to bulk chemicals and fine chemicals over heterogeneous catalysts. Green Chem. 2011, 13, 520-540. [CrossRef]

21. Mok, W.S.L.; Antal, M.J.; Varhegyi, G. Productive and parasitic pathways in dilute acid-catalyzed hydrolysis of cellulose. Ind. Eng. Chem. Res. 1992, 31, 94-100. [CrossRef]

22. Patil, S.K.R.; Lund, C.R.F. Formation and growth of humins via aldol addition and condensation during acid-catalyzed conversion of 5-hydroxymethylfurfural. Energy Fuels 2011, 25, 4745-4755. [CrossRef]

23. Girisuta, B.; Janssen, L.P.B.M.; Heeres, H.J. A kinetic study on the decomposition of 5-hydroxymethylfurfural into levulinic acid. Green Chem. 2006, 8, 701-709. [CrossRef]

24. Girisuta, B.; Dussan, K.; Haverty, D.; Leahy, J.J.; Hayes, M.H.B. A kinetic study of acid catalysed hydrolysis of sugar cane bagasse to levulinic acid. Chem. Eng. J. 2013, 217, 61-70. [CrossRef]

25. Rivas, S.; Vila, C.; Alonso, J.L.; Santos, V.; Parajó, J.C.; Leahy, J.J. Biorefinery processes for the valorization of Miscanthus polysaccharides: From constituent sugars to platform chemicals. Ind. Crops Prod. 2019, 134, 309-317. [CrossRef]

26. Ren, H.; Zhou, Y.; Liu, L. Selective conversion of cellulose to levulinic acid via microwave-assisted synthesis in ionic liquids. Bioresour. Technol. 2013, 129, 616-619. [CrossRef] [PubMed] 
27. Sorokina, K.N.; Taran, O.P.; Medvedeva, T.B.; Samoylova, Y.V.; Piligaev, A.V.; Parmon, V.N. Cellulose Biorefinery Based on a Combined Catalytic and Biotechnological Approach for Production of 5-HMF and Ethanol. ChemSusChem 2017, 10, 562-574. [CrossRef]

28. Prat, D.; Wells, A.; Hayler, J.; Sneddon, H.; McElroy, C.R.; Abou-Shehada, S.; Dunn, P.J. CHEM21 selection guide of classical- and less classical-solvents. Green Chem. 2015, 18, 288-296. [CrossRef]

29. Ren, H.; Girisuta, B.; Zhou, Y.; Liu, L. Selective and recyclable depolymerization of cellulose to levulinic acid catalyzed by acidic ionic liquid. Carbohydr. Polym. 2015, 117, 569-576. [CrossRef]

30. Hayes, B.L. Recent advances in microwave-assisted synthesis. Aldrichimica Acta 2004, 37, 66-77. [CrossRef]

31. Song, J.; Han, B. Green chemistry: A tool for the sustainable development of the chemical industry. Natl. Sci. Rev. 2015, 2, 255-256. [CrossRef]

32. Peleteiro, S.; Santos, V.; Parajó, J.C. Furfural production in biphasic media using an acidic ionic liquid as a catalyst. Carbohydr. Polym. 2016, 153, 421-428. [CrossRef]

33. Peleteiro, S.; Rivas, S.; Alonso, J.L.; Santos, V.; Parajó, J.C. Utilization of ionic liquids in lignocellulose biorefineries as agents for separation, derivatization, fractionation, or pretreatment. J. Agric. Food Chem. 2015, 63, 8093-8102. [CrossRef]

34. Serrano-Ruiz, J.C.; Campelo, J.M.; Francavilla, M.; Romero, A.A.; Luque, R.; Menéndez-Vázquez, C.; García, A.B.; García-Suárez, E.J. Efficient microwave-assisted production of furfural from C5 sugars in aqueous media catalyzed by Brønsted acidic ionic liquids. Catal. Sci. Technol. 2012, 2, 1828-1832. [CrossRef]

35. Carvalho, A.V.; Da Costa Lopes, A.M.; Bogel-Łukasik, R. Relevance of the acidic 1-butyl-3-methylimidazolium hydrogen sulphate ionic liquid in the selective catalysis of the biomass hemicellulose fraction. RSC Advances 2015, 5, 47153-47164. [CrossRef]

36. Peleteiro, S.; Santos, V.; Garrote, G.; Parajó, J.C. Furfural production from Eucalyptus wood using an acidic ionic liquid. Carbohydr. Polym. 2016, 146, 20-25. [CrossRef] [PubMed]

37. Shen, Y.; Sun, J.K.; Yi, Y.X.; Wang, B.; Xu, F.; Sun, R.C. One-pot synthesis of levulinic acid from cellulose in ionic liquids. Bioresour. Technol. 2015, 192, 812-816. [CrossRef] [PubMed]

38. López, M.; Vila, C.; Santos, V.; Parajó, J.C. Manufacture of Platform Chemicals from Pine Wood Polysaccharides in Media Containing Acidic Ionic Liquids. Polymers 2020, 12, 1215. [CrossRef]

39. Garrote, G.; Parajó, J.C. Non-isothermal autohydrolysis of Eucalyptus wood. Wood Sci. Technol. 2002, 36, 111-123. [CrossRef]

40. Zhang, Z.; Zhao, Z.K. Microwave-assisted conversion of lignocellulosic biomass into furans in ionic liquid. Bioresour. Technol. 2010, 101, 1111-1114. [CrossRef]

41. Sievers, C.; Valenzuela-Olarte, M.B.; Marzialetti, T.; Musin, I.; Agrawal, P.K.; Jones, C.W. Ionic-liquid-phase hydrolysis of pine wood. Ind. Eng. Chem. Res. 2009, 48, 1277-1286. [CrossRef]

42. Teng, J.; Ma, H.; Wang, F.; Wang, L.; Li, X. Catalytic fractionation of raw biomass to biochemicals and organosolv lignin in a methyl isobutyl ketone/ $\mathrm{H}_{2} \mathrm{O}$ biphasic system. ACS Sustain. Chem. Eng. 2016, 4, 2020-2026. [CrossRef]

43. Rivas, S.; González-Muñoz, M.J.; Santos, V.; Parajó, C.J. Production of furans from hemicellulosic saccharides in biphasic reaction systems. Holzforschung 2013, 67, 923-929. [CrossRef]

(C) 2020 by the authors. Licensee MDPI, Basel, Switzerland. This article is an open access article distributed under the terms and conditions of the Creative Commons Attribution (CC BY) license (http://creativecommons.org/licenses/by/4.0/). 